\title{
40 ANOS DE MACABÉA, A MENOR MULHER DO MUNDO
}

\author{
Lucia Castello Branco*
}

Para Sérgio Antônio Silva, pelas mãos docemente abertas, fonte de amor às palavras.

RESUMO: Tomando como referência a edição comemorativa dos 40 anos de $A$ bora da estrela (Rocco, 2017), o artigo propõe uma leitura desse romance de Clarice Lispector, em articulação com um de seus contos, "A menor mulher do mundo", tendo como base as construções lacanianas acerca do "feminino" e a figura do "feminino de ninguém", proposta por Maria Gabriela Llansol, em sua obra.

PALAVRAS-CHAVE: Clarice Lispector; Feminino de ninguém; Macabéa; Mulher.

\section{E agora?}

Abro este livro de Clarice, entrando por seus olhos e por sua assinatura, que recobrem sua letra. A letra, não menos enigmática que o olhar, já anuncia o claro enigma de há de vir: Macabéa, quarenta anos depois. Sou, certamente, uma das fiéis que a leram ao longo das últimas quatro décadas. Mesmo assim, os olhos altivos de Clarice, na sobrecapa da edição comemorativa dos quarenta anos de $A$ hora da estrela, são ainda capazes de me comover. "Não deploramos sobre o corpo dela - a caligrafia", escreveu, certa vez, Maria Gabriela Llansol (LLANSOL, 2008, p. 82). Não a deploro, antes comovo-me com as mãos

* Escritora, psicanalista e Professora Titular em Estudos Literários da Faculdade de Letras (FALE) da Universidade Federal de Minas Gerais (UFMG). Doutora em Estudos Literários pela Universidade Federal de Minas Gerais. 
de Paloma Vidal, tocando as mãos de Olga Borelli e as de Clarice Lispector, nessa abertura "antes da hora". 1

"E agora?" - pergunto -, inserindo a interrogação onde Paloma parece ter afirmado. Como não ver, na caligrafia não deplorada, a mão queimada de Clarice, a mão da "pecadora queimada", a escrever, sem piedade, a história dessa "nordestina se olhando ao espelho" (LISPECTOR, 2017, p. 56)?

Tento me separar de Clarice. O texto de Bejamin Moser, prefaciando a edição americana da Trilogia dos Rebeldes, de Maria Gabriela Llansol, ao aproximar forçosamente Clarice e Llansol, me atrapalha, nesse movimento de separação. Porque Moser as trata como "ligeiramente" mortas (MOSER, 2017, p. 24). E, para quem sempre foi atravessada pelo sopro densamente vivo dessas escritoras, nada ali é ligeiro, nada ali é morto.

Vou adiante, na leitura dos textos críticos que se seguem aos manuscritos de Clarice e ao texto de $A$ hora da estrela, na bela edição comemorativa dos quarenta anos do livro. Deixo para Sérgio, meu "companheiro filosófico", ${ }^{2}$ autor da mais precisa leitura de $A$ hora da estrela ${ }^{3}$ que já li, a tarefa de comentar essa edição tão nobre de um texto em que a pobreza se coloca como o seu primeiro claro enigma. "Infelizmente, quanto mais pobre, com mais enfeites me enfeito”, Clarice teria confessado, certa vez, a Lúcio Cardoso. (LISPECTOR, 2002, p. 62).

Também eu me sinto pobre diante dessa opulência da menor mulher do mundo. E, quando percebo, vejo que ofertei a Macabéa um outro nome, que já estava lá, muito antes que essa outra mulher, com "seu tamanho pequeno corpo" (LISPECTOR, 2017, p. 73), nascesse. Haveria, de fato, entre elas, algum parentesco? Poderíamos, entre as duas, traçar uma tênue linha de equilíbrio? Talvez, se as duas forem lançadas, como funâmbulas, em direção ao que Llansol denominou de "feminino de ninguém". Talvez, se as lermos

\footnotetext{
${ }^{1}$ Refiro-me, aqui, ao belo prefácio de Paloma Vidal para a edição comemorativa dos quarenta anos de $A$ hora da estrela, intitulado "E agora - uma crônica do encontro com os manuscritos de $A$ bora da estrela.

2 "Companheiro filosófico" é o epíteto conferido por Llansol a Vergílio Ferreira, em Inquérito às quatro confidências. ${ }^{3}$ SILVA, Sérgio Antônio. A hora da estrela de Clarice.
} 
com nosso "sexo de ler" (LLANSOL, 2011, p. 20). Talvez, se formos capazes de suportar, quarenta anos depois, "essa pessoa ínfima e quase imponderável” (CIXOUS in LISPECTOR 2017, p. 132), sempre às vésperas de sua morte, sempre às vésperas da morte de Clarice. E, no entanto, sempre viva. Porque essa pessoa ínfima, quase mulher e mais que mulher, um dia assim se escreveu: pela força de um "sim".

\section{Antes da hora}

Antes de $A$ hora da estrela, Clarice Lispector escreveu, com o mesmo amargo humor desse livro, o conto "A menor mulher do mundo", incluído em Laços de família, de 1960. E aí, na perspectiva do explorador francês Marcel Pretre, que se encanta e se perturba com essa criaturinha negra, já podemos perceber um olhar comparável ao de Rodrigo S.M., diante de sua estranha personagem:

Entre mosquitos e árvores mornas de umidade, entre as folhas ricas do verde mais preguiçoso, Marcel Pretre defrontou-se com uma mulher de quarenta e cinco centímetros. Madura, negra, calada. "Escura como um macaco", informaria ele à imprensa, e que vivia no topo de uma árvore com seu pequeno concubino. Nos tépidos humores silvestres, que arredondam cedo as frutas e lhes dão uma quase intolerável doçura ao paladar, ela estava grávida. (LISPECTOR, 1973, p. 77-8).

Mas o que buscamos aqui não se reduz ao método comparatista, pois é mesmo do incomparável que se trata: a menor mulher do mundo. É por "exercício de aproximação"4 que colocamos lado a lado uma mulher, outra mulher. E, se "não há A Mulher", como proferiu Lacan, com o "artigo definido para designar o universal” (LACAN, 1985, p. 98), talvez seja apenas tomando-as uma a uma que possamos, de alguma maneira, abordá-

\footnotetext{
${ }^{4}$ Fazemos alusão, aqui, ao belo título e ao método de leitura de Silvina Rodrigues Lopes, em Exercícios de aproximação.
} 
las. Porque não é desconsiderável, em nenhum desses dois textos, o fato de essas personagens serem mulheres. Tampouco é desconsiderável o fato de, nos dois textos, essas mulheres serem objetos de investigação de um homem, seja ele um explorador, seja um narrador. Mas não nos enganemos acerca desses homens: eles se perturbam, mas não vacilam. "Ainda bem que o que vou escrever já deve estar de certo modo escrito em mim" - declara Rodrigo S.M. (LISPECTOR, 2017, p. 55). Ao que Marcel Pretre poderia, talvez, acrescentar: "Você é Pequena Flor” (LISPECTOR, 1973, p. 79). Dando um nome familiar à estranheza daquela mulher ínfima, quem sabe ele a compreenderia?

Mas a estranheza sempre prevalece, em Clarice. E mesmo um explorador, em franca atividade de pesquisa, é capaz de se perturbar diante daquela pequenez de mulher:

Ali em pé estava, portanto, a menor mulher do mundo. Por um instante, no zumbido do calor, foi como se o francês tivesse inesperadamente chegado à conclusão última. $\mathrm{Na}$ certa, apenas por não ser louco é que sua alma não desvairou nem perdeu os limites. Sentindo necessidade imediata de ordem, e de dar nome ao que existe, apelidou-a de Pequena Flor. E, para conseguir classificá-la diante das realidades reconhecíveis, logo passou a colher dados a seu respeito (LISPECTOR, 1973, p. 78).

Tal atitude não é muito diferente da de Rodrigo S.M., quando, perturbado por essa mulher "sem floração", que "não faz falta a ninguém”, descobre que também ele não faz falta e, talvez por isso, tenha a necessidade de se afirmar homem, para que não corra o risco de "lacrimejar piegas":

Mas a moça de quem falarei mal tem corpo para vender, ninguém a quer, ela é virgem e inócua, não faz falta a ninguém. Aliás - descubro eu agora - também eu não faço a menor falta e até o que escrevo um outro escreveria. Um outro escritor, sim, mas teria que ser homem porque escritora mulher pode lacrimejar piegas. (LISPECTOR, 2017, p. 49)

É surpreendente, nesse trecho da narrativa, que Rodrigo S.M. precise se afirmar como homem, quando esta é, já no início do romance, a sua peremptória declaração: “A 
história - determino com falso livre-arbítrio - vai ter uns sete personagens e eu sou um dos mais importantes deles, é claro. Eu, Rodrigo S.M.” (LISPECTOR, 2017, p. 48). Assim como o nome "Pequena Flor" parece nascer da necessidade de ordem, para Marcel Pretre, e de "dar nome ao que existe", a assinatura "Rodrigo S.M.", ofertada ao leitor pelo próprio narrador, parece nascer da necessidade de impor uma certa ordem, uma “ordem masculina", ao universo excessivamente feminino de uma história que, aos poucos, vai se abrindo a um "feminino de ninguém".

Mas tudo já havia começado, antes de começar, por uma “dedicatória do Autor", seguida de uma verdade: "Na verdade, Clarice Lispector", lê-se, nos parênteses explicativos dessa dedicatória. A quem dedicar essa coisa-Macabéa? A Schumann, Beethoven, Chopin, Strauss, Bach, Debussy, Schönberg, mas também “aos gnomos, anões, sílfides e ninfas que habitam a vida" (LISPECTOR, 2017, p. 45). Pois o livro que se segue, o autor avisa, é uma meditação sobre o nada. Ou sobre o ninguém?

"Como uma caixa dentro de uma caixa, dentro de uma caixa, obedecendo talvez à necessidade que a Natureza tem de exceder a si própria” (LISPECTOR, 1973, p. 77), Macabéa já estava lá, em “A menor mulher do mundo”. Talvez nunca tenhamos pensado nela assim, como a menor de uma espécie que não existe. Afinal, "até mesmo o fato de vir a ser uma mulher não parecia pertencer a uma vocação” (LISPECTOR, 2017, p. 60). Ela, esse "minúsculo fragmento de vida humana", nas palavras de Hélène Cixous (CIXOUS in LISPECTOR, 2017, p. 132), essa que "somente vive, inspirando e expirando, inspirando e expirando” (LISPECTOR, 2017, p. 56), “essa quase mulher é uma mulher quase não mulher, mas é de tal modo quase não mulher que talvez seja mais mulher que toda mulher" (CIXOUS in LISPECTOR, 2017, p. 134). Esta, a ínfima porção da que não existe, nãotoda mulher, aqui a chamaremos, em consonância com Maria Gabriela Llansol, de "feminino de ninguém”. 


\section{Depois da hora}

O "feminino de ninguém" é uma figura que surge no livro Lisboaleiprig 2: o ensaio de música, de Maria Gabriela Llansol, como um feminino de Aossê, figura llansoliana metamorfoseada a partir de Fernando Pessoa. Tendo gerado mais de setenta heterônimos e centenas de poemas, o poeta não se deteve, em sua obra, nem na figura do feminino, nem na temática do amor, como é comum na poesia ocidental. Como observa Octavio Paz, o amor e o feminino são temas que ocupam a obra de Pessoa por negatividade, como ausência:

O Cancioneiro: mundo de poucos seres e muitas sombras. Falta a mulher, o Sol central. Sem mulher, o universo sensível desvanece-se, não há nem terra firme, nem água, nem encarnação do impalpável. Faltam os prazeres terríveis. Falta a paixão, este amor que é desejo de um ser único, qualquer que seja (PAZ, 1992, p. 38-39).

Assim, a Pessoa-Personne, essa "máscara de ninguém”, como sugere Leyla Perrone-Moisés, ${ }^{5}$ corresponderá, na obra de Llansol, a um "feminino de ninguém", não referido ao masculino, mas antes a uma ausência de masculino, ou mesmo de pessoa (agora com minúsculas), a um para além do humano, talvez. Vejamos como isso se dá, em Lisboaleiprig 2:

Passeava-se distraidamente por Lisboa quando passou por ele uma mulher nova. Sentiu-lhe os seios baterem livres contra a camisa, as pernas e o garbo da garupa (não tinha palavra melhor) caminharem sem entraves como luzes fátuas vistas na luz translúcida de um balão veneziano. Aquele movimento era um misto de substância viva, aragem firme, e luz trémula. Passou por mim foi o que pensou mais tarde, e guardou como expressão exacta um porte altivo e um vestido ao vento.

\footnotetext{
${ }^{5}$ PERRONE-MOISÉS, Leyla. Fernando Pessoa: aquém do eu, além do outro. No primeiro capítulo desse livro, "Pessoa Ninguém?", texto escrito originalmente em francês, Leyla Perrone-Moisés faz uma leitura que persegue o seguinte deslizamento de significantes: pessoa-personne-máscara-ninguém. Assim, conclui que a máscara heteronímica em Pessoa não recobre um rosto consistente, mas uma ausência, um ninguém.
} 
Não é correcto dizer que Aossê nunca a viu. Vira-a, mas sem o rosto. Normalmente, é verdade que o verbo ver alguém supõe um rosto, conhecido ou a conhecer. Não vira ninguém é correcto, mas vira ninguém não é menos próprio: um rosto sem rosto. Fora-lhe mostrado - dir-se-ia - à medida das suas posses [...]

Deram-lhe um feminino de ninguém a ver. Viva, veloz, livre, altiva. (LLANSOL, 1994, p. 37)

Os que conhecem a obra de Llansol sabem que esse "feminino de ninguém" como um "vestido ao vento" vai, de certa forma, reaparecer em outra figura: a da rapariga desmemoriada. Essa figura, que vamos encontrar no livro O Jogo da liberdade da alma, de 2003, essa rapariga que não se lembra nem de seu próprio nome, é também, ao final desse livro, reduzida a um vestido, um vestido sem corpo, mas absolutamente sensual. E esse vestido sem corpo, esse "feminino de ninguém”, renuncia, enfim, ao homem. O que esse livro propõe radicalmente é algo que já vinha sendo construído nos textos de Llansol: a constituição de um feminino para além da referência ao falo, como lemos na citação a seguir: "o homem tem de renunciar ao poder, e a mulher ao homem” (LLANSOL, 2003, p. 30). Esse feminino talvez possa ser aproximado do que Llansol denominará de “terceiro sexo": a paisagem. Em “A boa nova anunciada à natureza”, leremos:

Tudo participa das diversas partes: a boca, a copa frondosa, o cogumelo, a falésia, o mar, a erva rasteira, a leve aragem, os corpos dos amantes. Os três sexos que movimentam a dança do vivo: o homem, a mulher, a paisagem.

Esta é a novidade: a paisagem é o terceiro sexo.

A paisagem não tem um sexo simples. Nem o homem, nem a mulher. (LLANSOL, 2000, p. 44)

Se "tudo participa das diversas partes" e, se a paisagem é o terceiro sexo, então o feminino, fora da lógica binária, não é mais referido ao masculino e pode, afinal, se expandir em direção ao cogumelo, à falésia, ao mar, à erva rasteira, como um feminino de PessoaPersonne, como um "feminino de ninguém". 
O pensamento de Lacan, no Seminário 20, ao dizer, a partir de sua investigação acerca do gozo feminino, que "Não há A Mulher", ${ }^{6}$ apontando para a lógica do não-todo e também para a ausência, pode ser aproximado do que Llansol denominará de "existentenão-real": aquilo que existe sem correspondente na realidade, aquilo que, não podendo ser generalizado, não se "realiza” como linguagem, no campo do simbólico. ${ }^{7}$

Mas parece-me que é em seu último seminário, "A topologia e o tempo", que Lacan avançará, ainda que de maneira bastante enigmática, em direção ao que podemos denominar, a partir de Llansol, de "feminino de ninguém”. Pois aí já não se trata apenas da singularidade do gozo feminino, mas da existência de um terceiro sexo, que não poderia subsistir diante dos outros dois. Ou, nas palavras de Lacan,

Não há relação sexual, é o que tenho enunciado. O que é recolocado ali? Dado que todos os que se entendem por gente, ou seja, os seres humanos, fazem o amor. Há para isso uma explicação: a possibilidade - notemos que o possível é o que definimos como o que cessa de se escrever - a possibilidade de um terceiro sexo. Por outro lado, porque é que há dois? Isso se explica mal.

A linguagem tem suas leis das quais a universalidade é o modelo, a particularidade não o é menos. O que o imaginário faz é imaginar o Real: é uma reflexão. Uma reflexão tem a ver com o espelho, é, pois, no espelho que exerce uma função. O espelho é o mais simples dos aparatos. É uma função de alguma maneira totalmente natural. (LACAN, 1979, p. 103)

Ora, se estamos fora da lógica do espelho, estamos fora do binarismo, fora de uma função “totalmente natural” e talvez até mesmo fora de uma lógica do humano, como

${ }^{6}$ LACAN. O Seminário. Livro 20. Mais, ainda. Nesse seminário, Lacan investigará a questão do gozo feminino, articulando-a ao gozo místico e à lógica do não-todo. A esse respeito, ver sobretudo a lição "Deus e O Gozo d'A Mulher".

${ }^{7} \mathrm{Na}$ obra de Llansol, encontramos duas figuras que, ora se opõem, ora se tangenciam: o "real-não-existente" e o “existente-não-real”. Pode-se dizer, muito rapidamente, que o "real-não-existente" de certa maneira corresponderia à lógica realista, da verossimilhança: o que tem realidade, mas, de fato, não existe. Já o "existente-nãoreal" corresponde à lógica do fulgor: existe, ex-iste, sem possuir, necessariamente, um correspondente na realidade factual. 
propõe Llansol, através da inserção de um terceiro: a paisagem como o terceiro sexo. Cabe, então, indagarmos se esse terceiro sexo, proposto por Llansol - e talvez intuído por Lacan -, não compreenderia uma outra lógica - uma topologia, talvez - que, fora da lógica dual, conceberia um feminino não referido ao masculino, um "feminino de ninguém".

É também em direção a um "feminino de ninguém” que veremos a questão do feminino avançar, na obra de Clarice Lispector. Numa rápida leitura do conto "Amor", de 1950, observaremos aí ainda a tentativa de garantir certa consistência ao feminino, a partir de sua referência ao falo, ao masculino. Nesse conto, em que a protagonista, tão próxima da própria Clarice Lispector, vê seu mundo ruir, a partir da visão de um cego mascando chicletes, verifica-se, ao final da narrativa, uma certa reconstituição dessa mulher, justamente na cena em que ela se olha no espelho e se reconhece a partir do apaziguamento que seu marido, ao chegar em casa, lhe traz de volta. Estamos, aí, no campo da "função do espelho”, “o mais simples dos aparatos”, segundo Lacan. “E, se atravessara o amor e o seu inferno, penteava-se agora diante do espelho, por um instante sem nenhum mundo no coração. Antes de se deitar, como se apagasse uma vela, soprou a pequena flama do dia” (LISPECTOR, 1973, p. 30).

Já em Água viva, de início, o feminino que aí se escreve não se refere ao masculino, mas abre-se ao campo de um terceiro sexo que, nesse livro, se constrói como o neutro: ${ }^{8} \mathrm{O}$ it , o "mistério do impessoal", que já não se refere a um "eu" e menos ainda a um "ele" ou a um "ela", mas à própria "vida vista pela vida". Ou, em outras palavras da própria narrativa: "Não vou ser autobiográfica. Quero ser 'bio”" (LISPECTOR, 1973, p. 40)

Curiosamente, esse "bio", que se aproxima do que Llansol chamaria "o vivo", situa-se antes da diferença dos sexos, no mundo puramente orgânico da placenta. Por isso, a narradora declara: “Ainda não estou pronta para falar em 'ele' ou 'ela”,; "Nasci há alguns

\footnotetext{
${ }^{8}$ A respeito do neutro, lemos, em Blanchot: "Escrever é entregar-se à ausência de tempo. Neste ponto, estamos abordando, sem dúvida, a essência da solidão. A ausência de tempo não é um modo puramente negativo [...] Longe de ser um modo puramente negativo é, pelo contrário, um tempo sem negação, sem decisão, quando aqui é igualmente lugar nenhum, cada coisa retira-se em sua imagem e o 'Eu' que somos reconhece-se ao soçobrar na neutralidade de um 'Ele' sem rosto." (BLANCHOT, 1987, p. 20).
} 
instantes e estou ofuscada" (LISPECTOR, 1973, p. 25). E, no entanto, é no feminino que a narrativa se escreve: trata-se de uma narradora, um feminino, mas é como "feminino de ninguém" - água viva - que esse feminino se inscreve. Ouçamo-lo: "Um novo personagem atravessa a planície deserta e desaparece mancando. Ouve-se: psiu; psiu! E chama-se ninguém”. (LISPECTOR, 1973, p. 65).

Ainda em "A menor mulher do mundo", conto que faz parte da mesma coletânea em que se inclui o conto "Amor", o "feminino de ninguém" pode ser entrevisto pela aproximação da ínfima mulher aos elementos da natureza, como é nítido na construção dessa personagem "escura como um macaco", que levava em seu ventre um "filho mínimo" e que vivia no alto das árvores.

Pode-se dizer, então, que Macabéa, nascida às vésperas da morte de Clarice e de sua própria morte, de certa maneira já começara, "antes da hora”, antes de começar, como essa história de uma mulher quase não mulher, mais que mulher, "porque antes da préhistória havia a pré-história da pré-história” (LISPECTOR, 2017, p. 47) e havia também "o nunca" e o feminino de ninguém.

Percorrendo, assim, esses três textos de Clarice a partir de uma figura llansoliana, diremos, com Lacan, que "Não há A Mulher". Mas, tomando, sobretudo, o partido da poesia e dos poetas - o partido da caligrafia não deplorada: a letra -, ao lado de Clarice, Llansol e Mallarmé, diremos também: "sim”. A mulher, assim como a literatura, sim, ela ex-iste, como existente-não-real, como feminino de ninguém. "E, se quiserem, sozinha, à exceção de tudo." 9

${ }^{9}$ Apropriamo-nos aqui da célebre formulação de Mallarmé - "Sim, que a literatura existe, e se quiserem, sozinha, à exceção de tudo". Fazemos equivaler, portanto, a literatura e a mulher, como se ambas ex-istissem absolutamente, enquanto existentes não reais. MALLARMÉ, Stéphane. Oeuvres complètes. p. 63: La musique et les lettres. 


\section{YEARS OF MACABÉA, THE WORLD'S SMALLEST WOMAN}

ABSTRACT: Having by reference the edition that celebrates the 40th anniversary of $A$ bora da estrela (Rocco, 2017), the article proposes a reading of this Clarice Lispector novel, in relation with one of her short stories, "A menor mulher do mundo", based on the lacanian constructions about the "feminine" and the figure of "the feminine of nobody", proposed by Maria Gabriela Llansol, in her literary work.

KEYWORDS: Clarice Lispector; Macabéa; The feminine of nobody; Woman.

\section{REFERÊNCIAS:}

BLANCHOT, Maurice. O espaço literário. Rio de Janeiro: Rocco, 1987.

LACAN, Jacques. O Seminário. Livro 20. Mais, ainda. 2. ed. Rio de Janeiro: Zahar, 1985. . O Seminário: Livro 26; a topologia e o tempo. 1979. Inédito.

LISPECTOR, Clarice. Laços de família: contos. 5. ed. Rio de Janeiro: Sabiá, 1973. - Água viva. Rio de Janeiro: Rocco, 1973.

. Correspondências. Rio de Janeiro: Rocco, 2002. p. 62: Carta a Lucio Cardoso. - A hora da estrela. Rio de Janeiro: Rocco, 2017.

LLANSOL, M. G. Lisboaleiprig 2: o ensaio de música. Lisboa: Rolim, 1994. . Onde vais, Drama-Poesia? Lisboa: Relógio D'Água, 2000.

- O Jogo da liberdade da alma. Lisboa: Relógio D’Água, 2003.

. Os cantores de leitura. Lisboa: Assírio \& Alvim, 2007.

- Inquérito às quatro confidências. Belo Horizonte: Autêntica, 2011.

LOPES, Silvina Rodrigues. Exercícios de aproximação. Lisboa: Vendaval, 2003.

MALLARMÉ, Stéphane. Oeuvres completes. Paris: Gallimard, 1998-2003. V. 2.

MOSER, Benjamin. A poeta do póstumo. Quatro cinco um, São Paulo: Abril Cultural, 2017, p. 24. [Prefácio à edição americana da Trilogia dos Rebeldes, de Maria Gabriela Llansol].

PAZ, O. Fernando Pessoa, o desconbecido de si mesmo. Lisboa: Veja, 1992.

PERRONE-MOISÉS, L. Fernando Pessoa: aquém do eu, além do outro. São Paulo: Martins Fontes, 2001.

SILVA, Sérgio Antônio. A hora da estrela de Clarice. Belo Horizonte: Autêntica, 2005.

Recebido em: 20/10/2017.

Aprovado em: 18/12/2017. 